\title{
Minimally Invasive Partial Nephrectomy in the Era of Robotic Surgery
}

\author{
(i) Hakan Bahadir Haberal, (1) Meylis Artykov, (1) Ahmet Gudeloglu, (i) Sertac Yazici, (1) Cenk Yucel Bilen \\ Department of Urology, Hacettepe University Faculty of Medicine, Ankara, Turkey
}

\begin{abstract}
Objectives: The objectives of the study were to compare the operative features, complication rates, functional, and pathological outcomes of laparoscopic partial nephrectomy (LPN) and robotic-assisted partial nephrectomy (RPN).

Methods: The demographics, perioperative, and follow-up data of patients who underwent partial nephrectomy between January 2007 and April 2020 with minimally invasive methods were retrospectively analyzed. Patients with minimum 3 months follow-up were enrolled in the present study. Perioperative and pathological outcomes were compared between the patients underwent LPN and RPN.

Results: A total of 85 patients (65 LPN and 20 RPN) were included in the present study. The mean patient age at the time of surgery was $56.31 \pm 10.48$ years. Female-to-male ratio was 30/55. Patients in the RPN group had higher R.E.N.A.L. and PADUA scores $(p=0.039$ and $p=0.030$, respectively). Median warm ischemia time, median operation time, median intraoperative estimated blood loss, mean post-operative hemoglobin change, and median hospitalization time were similar between groups $(p=0.133, p=0.753$, $p=0.079, p=0.882$, and $p=0.473$, respectively). Artery-only clamping rate was significantly higher in RPN group ( $p=0.033$ ). The cost of RPN was significantly greater than LPN $(\mathrm{p}<0.001)$. Transfusion rates, post-operative complication rates, percent of estimated glomerular filtration rate change at the last follow-up, and trifecta achievement were similar between the groups $(p=0.622, p=0.238$, $\mathrm{p}=0.428$, and $\mathrm{p}=0.349$, respectively).

Conclusion: In this series, similar perioperative and functional outcomes were achieved by RPN compared to LPN in more complex renal masses.
\end{abstract}

Keywords: Intraoperative complications; laparoscopic surgery; nephrectomy; robotic surgical procedures; treatment outcome.

Please cite this article as "Haberal HB, Artykov M, Gudeloglu A, Yazici S, Bilen CY. Minimally Invasive Partial Nephrectomy in the Era of Robotic Surgery. Med Bull Sisli Etfal Hosp 2021;55(2):167-172".

A t present, European Association of Urology guidelines strongly recommend partial nephrectomy $(\mathrm{PN})^{[1]}$ for $\mathrm{CT} 1$ renal masses. ${ }^{[2]} \mathrm{PN}$ can be performed, either with an open, laparoscopic, or robotic-assisted approaches. The basic principles of modern PN were first reported by Vermooten in 1950. ${ }^{[3]}$ Laparoscopic PN (LPN) was first introduced by Winfield et al. in 1993. ${ }^{[4]}$ With the introduction of robotic systems in surgical procedures, Gettman et al. published the first robotic-assisted PN (RPN) series in 2004..$^{[5]}$ The rate of PN for treatment of renal masses has increased over time. ${ }^{[6]}$

Nowadays, the rate of renal masses incidentally diagnosed constitutes more than half of all renal masses. ${ }^{[7]}$ As a result of this, surgical interventions for small renal masses have increased. This trend was followed by raise of interest in minimally invasive surgery in effort to reduce morbidity and hospitalization time and expedite recovery after surgery. ${ }^{[8]}$ Various studies have been conducted to investigate the impact of different approaches of $\mathrm{PN}$ on perioperative

Address for correspondence: Hakan Bahadir Haberal, MD. Hacettepe Universitesi Tip Fakultesi, Uroloji Anabilim Dali, Ankara, Turkey Phone: +90 5330391907 E-mail: bahadirhaberal@gmail.com

Submitted Date: Jule 23, 2020 Accepted Date: September 08, 2020 Available Online Date: July 02,2021

${ }^{\circ}$ Copyright 2019 by The Medical Bulletin of Sisli Etfal Hospital - Available online at www.sislietfaltip.org

OPEN ACCESS This is an open access article under the CC BY-NC license (http://creativecommons.org/licenses/by-nc/4.0/). 
outcomes; however, these studies achieved inconclusive results. ${ }^{[1,9-14]}$

In this study, we present our experience in minimally invasive PN. We reported the operative features, complication rates, functional, and pathological outcomes of LPN and RPN. We hypothesized that implementation of RPN improved the perioperative results after PN.

\section{Methods}

This study was performed with the approval of the Local Ethics Committee of Hacettepe University (June 23, 2020/ GO 20/584). Since 2007, 104 patients underwent PN by minimally invasive methods (LPN or RPN) due to solitary renal masses in a single institution. Patients converted to open surgery or eventually radical nephrectomy, and those with missing data were excluded from the study. Patients with at least 3 months of follow-up were enrolled in the pre-sent study. In total, the data of 85 consecutive patients were retrospectively analyzed in the present study.

All patients in the study were operated with a transperitoneal approach by three surgeons experienced in minimally invasive surgery depending on initial assignment at referral. Patients were informed in detail about both surgical methods. After then, the patients made their choices about the surgical method. Warm ischemia method and the use of intraoperative ultrasound were determined in accordance with primary surgeon's discretion.

Patients were divided into two groups according to the surgical method applied, LPN or RPN. Groups were compared in terms of gender, age, body mass index (BMI), lesion side, lesion size, clinical stage, R.E.N.A.L. score, ${ }^{[15]}$ PADUA score, ${ }^{[16]}$ SPARE score, ${ }^{[17]}$ American Society of Anesthesiologists score, Charlson comorbidity index (CCl), operation time (excluding docking time in RPN group) (min), post-operative complications, ischemia type (nonischemic, hilar clamping, artery only clamping or selective arterial clamping), warm ischemia time (WIT) (min), post-operative estimated glomerular filtration rate (eGFR) change, last follow-up eGFR change, post-operative hemoglobin change, estimated blood loss (EBL) $(\mathrm{mL})$, blood transfusion rates, hospitalization time (days), total cost of surgical procedures, and trifecta achievement. eGFR was estimated using The Modification of Diet in Renal Disease formula. ${ }^{[18]}$ Tumors were categorized according to the 2017 TNM staging system. ${ }^{[19]}$ Post-operative (30-day) complications were compared between the groups with the Clavien-Dindo classification. ${ }^{[20]}$ Post-operative complications were classified as minor (Grade 1-2) and major ( $\geq$ Grade 3) complications. Trifecta defined as the combination of negative surgical margins, no intraoperative and 90-day post-operative complications, and WIT $<25$ min. ${ }^{[21]}$

\section{Statistical Analysis}

All statistical analyses were performed using the Statistical Package for the Social Sciences 24.0 (IBM Corp., Chicago) software for Windows. Kolmogorov-Smirnov test was used to determine the normality of data. For univariate analysis, the Chi-square test was used for nominal data, the Student-t-test was used for parametric variables, and the Mann-Whitney U-test was used for non-parametric variables. Mean \pm standard deviation is used for parametric variables, while median and interquartile range is used for nonparametric variables. $\mathrm{P}<0.05$ was considered statistically significant.

\section{Results}

A total of 85 patients ( $65 \mathrm{LPN}$ and $20 \mathrm{RPN}$ ) were included in the present study. The mean patient age at the time of surgery and median follow-up period was $56.31 \pm 10.48$ years and 12 (3.5-34.50) months, respectively. Female-to-male ratio was 30/55.

Patients in the RPN group had larger tumor size, higher cT1b tumor rate, and higher R.E.N.A.L. and PADUA scores $(p=0.005, p=0.011, p=0.039$, and $p=0.030$, respectively). The patients' demographics and preoperative features are summarized in Table 1.

Median WIT, median operation time, median intraoperative $E B L$, mean post-operative hemoglobin change, median post-operative eGFR change percent, and median hospita-lization time were similar between groups $(p=0.133$, $p=0.753, p=0.079, p=0.882, p=0.509$, and $p=0.473$, respectively). Artery-only clamping rate was significantly higher in RPN group ( $80 \%$ vs. $43.1 \%, p=0.033$ ). The cost of RPN procedure was significantly greater than LPN $(p<0.001)$ (Table 2$)$.

Intraoperative and post-operative transfusion rates were $2.4 \%$ and $5.9 \%$, respectively. Transfusion rates were similar between the LPN and RPN groups $(p=0.622)$. The number of patients with Clavien Grades 1, 2 and 3a complications were 5 (5.9\%), 8 (9.4\%), and 2 (2.4), respectively. Post-operative complication rates were similar between groups $(p=0.238)$ (Table 2).

Malign pathology was detected in 65 (76.5\%) patients. The most common types of malign pathology were clear cell carcinoma $(n=44,51.8 \%)$, papillary carcinoma $(n=13$, $15.3 \%)$, and chromophobe carcinoma $(n=4,4.7 \%)$. Pathological outcomes were similar between groups (Table 3 ).

Functional outcomes are summarized in Table 3. Percent of eGFR change at the last follow-up was similar between groups $(p=0.428)$. The trifecta rate was $54.1 \%$ and there was no difference between two groups for trifecta achievement $(p=0.349)$. 
Table 1. Demographics and pre-operative data

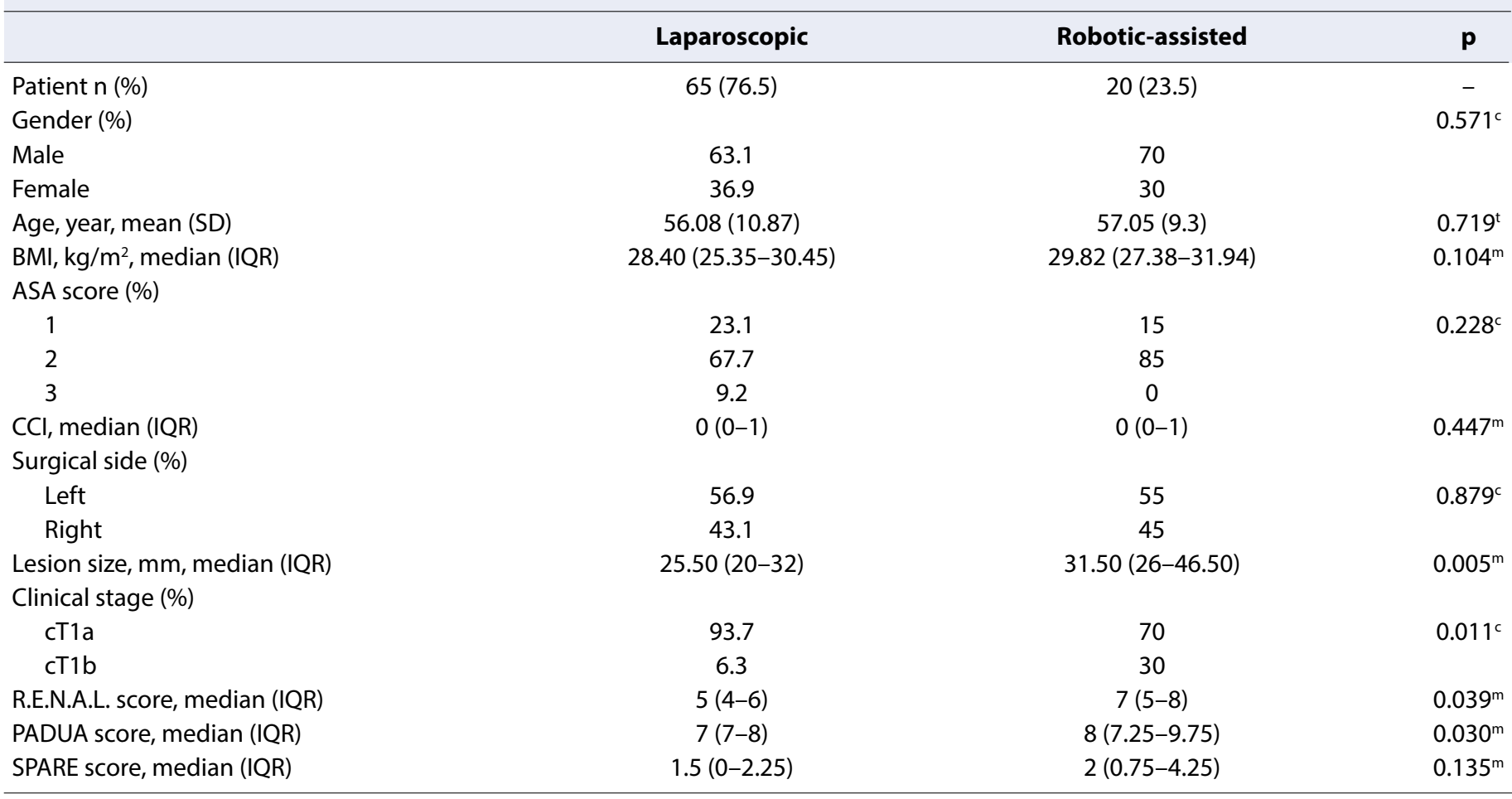

c: Univariate analysis (Chi-square test); ${ }^{\mathrm{m}}$ : Univariate analysis (Mann-Whitney U-test); ${ }^{\text {: }}$ Univariate analysis (Student-t-test); ASA: American Society of Anesthesiologists; BMI: Body mass index; CCl: Charlson comorbidity index; IQR: Interquartile range; SD: Standard deviation.

Table 2. Comparison of perioperative outcomes between groups

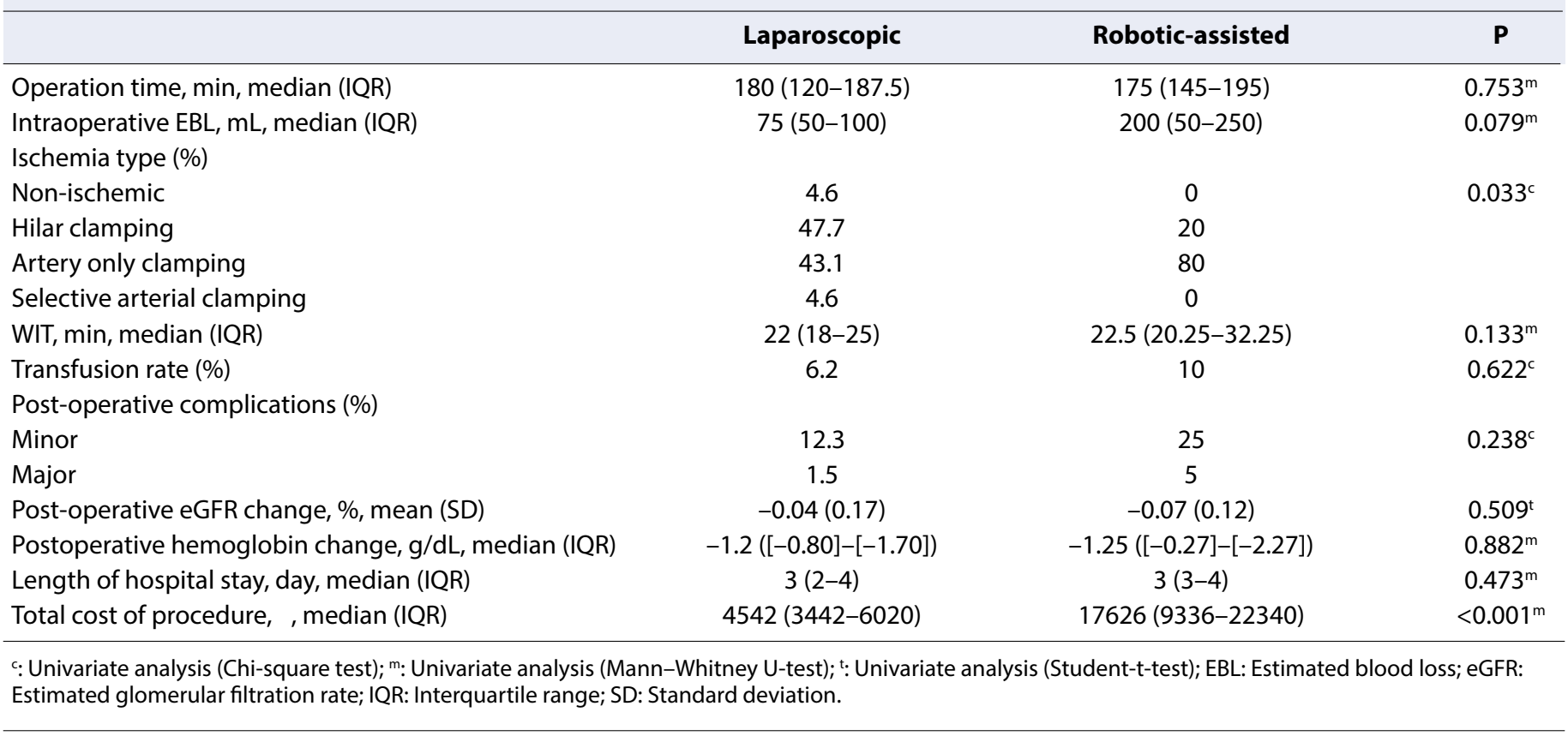

\section{Discussion}

Closely following recent advancements in medical technology, important changes occur in field of contemporary surgical practice. Adaptation of robotic systems to surgi- cal procedures has widened the domain of minimally invasive surgery. ${ }^{[8]}$ With the spread of robotic systems, the rate of RPN increased significantly. ${ }^{[22]}$ Consistently, the rate of minimally invasive PN has increased over the years. ${ }^{[6]}$ In 
Table 3. Pathological and functional outcomes of patients

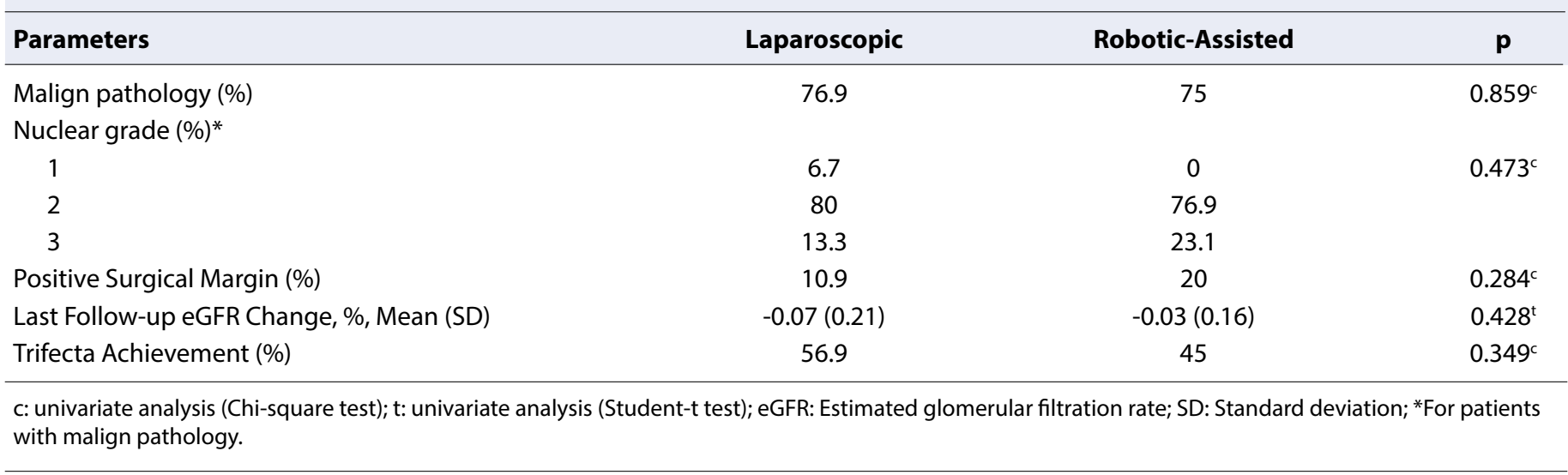

this study, we aimed to evaluate our minimally invasive PN experience since introduction of robotic surgery system in our institution.

One of the most important concerns about PN is renal ischemia. Renal ischemia was shown to be one of the most important and modifiable parameter in the preservation of kidney function after PN. ${ }^{[23]}$ Cao et al. reported in their meta-analysis that arterial-only clamping provided better results in preserving long-term kidney function than hilar clamping. ${ }^{[24]}$ In our study, the rate of arterial-only ischemia was significantly higher in the RPN group compared to LPN group; however, there was no difference between groups in long-term eGFR change. We believe that limited number of patients in the RPN group affected this result. Robotic surgery offers superior dexterity compared to laparoscopic instruments when achieving selective renal ischemia, with the advantages of magnified 3D vision, flexibility of the instruments, and elimination of tremor. ${ }^{[25]}$ From this aspect, RPN may be of advantage in preserving long-term kidney function.

The current literature has inconsistencies regarding the effect of RPN on perioperative outcomes after PN. Leow et al. and Wu et al. stated that RPN provide superior perioperative outcomes; while Alimi et al. and Aboumarzouk et al. reported comparable perioperative outcomes between RPN and LPN. ${ }^{[1,12-14]}$ In our study, similar perioperative outcomes were determined between the two groups. The factors responsible for discrepancy between studies were thought to be the heterogeneity in study populations as well as different levels of experience in minimally invasive surgery. A randomized prospective multicentric study seems to the best method to address these issues.

Another discussion topic regarding robotic surgery is the financial cost. Mir et al. ${ }^{[26]}$ showed that, RPN had the heaviest financial burden for procedure while the most costeffective method was LPN. Similarly, Laydner et al. ${ }^{[27]}$ re- ported that RPN was the most expensive method for PN due to the cost of instruments and necessary supplies. In consistent with the literature, the cost of RPN was found to be significantly higher than LPN in our study. For roboticassisted surgery to become the standard minimally invasive procedure in $\mathrm{PN}$, it is vital for the system to evolve in much sustainable direction. Further modification, not necessarily simplification, in operating process will hopefully resolve the problem of maintenance cost without diminishing practical convenience of the robotic system.

The short learning curve is one of the most important advantages of RPN compared to LPN. ${ }^{[28]}$ It has been shown that transitioning from LPN to RPN had even shorter learning curve. ${ }^{[29]}$ In our study, all surgeons had enough experience in laparoscopic surgery at the time they made their transition from laparoscopic to robotic surgery. In accordance with the literature, surgeons in our study reached similar proficiency level in robotic-assisted approach with fewer cases, keeping in mind their familiarity with laparoscopy. In addition, the patients who underwent RPN in our institution had tendency to have more complex and lar-ger renal masses. We might speculate that the reasonable learning curve of RPN may have played a role in achieving perioperative outcomes similar to LPN while operating more complex renal masses.

The main limitations of our study are the single-center data, retrospective design, and limited follow-up period. Second, our study includes a limited number of patients. Third, the patients in our study were operated by three different surgeons. This situation may be considered as another limitation. Finally, in our study, the mean tumor size is $<3 \mathrm{~cm}$. As the tumor size increases, there may be differences between the groups in terms of complication rates. This situation was considered as an another limitation of our study. However, the high experience of these surgeons in minimally invasive surgery ( $>100$ cases) minimizes the impact of this limitation. 


\section{Conclusion}

In this series, the RPN facilitated a minimally invasive approach in the treatment of more complex renal masses with similar complication and success rates. The RPN provides the feasibility of artery-only ischemia more successfully than LPN. However, the high financial cost of RPN should be kept in mind during the selection of treatment method.

\section{Disclosures}

Ethics Committee Approval: Local Ethics Committee of Hacettepe University (June 23, 2020/GO 20/584).

Peer-review: Externally peer-reviewed.

Conflict of Interest: None declared.

Authorship Contributions: Concept - H.B.H., M.A., S.Y.; Design - A.G., S.Y., C.Y.B.; Supervision - C.Y.B.; Materials - A.G., S.Y., C.Y.B.; Data collection \&/or processing - H.B.H., M.A.; Analysis and/or interpretation - H.B.H., M.A.; Literature search - H.B.H., A.G.; Writing - H.B.H., M.A., S.Y.; Critical review - A.G., C.Y.B.

\section{References}

1. Leow JJ, Heah NH, Chang SL, Chong YL, Png KS. Outcomes of Robotic versus Laparoscopic Partial Nephrectomy: an Updated Meta-Analysis of 4,919 Patients. J Urol. 2016;196:1371-7. [CrossRef]

2. Ljungberg B, Albiges L, Bensalah K, Bex A, Giles RH, Hora M, et al. EAU Guidelines on Renal Cell Carcinoma. presented at the EAU Annual Congress Amsterdam; 2020. Available at: https://uroweb. org/wp-content/uploads/EAU-Guidelines-on-Renal-Cell-Carcinoma-2020.pdf. Accessed Apr 8, 2021.

3. Vermooten $\mathrm{V}$. Indications for conservative surgery in certain renal tumors: a study based on the growth pattern of the cell carcinoma. J Urol 1950;64:200-8. [CrossRef]

4. Winfield HN, Donovan JF, Godet AS, Clayman RV. Laparoscopic partial nephrectomy: initial case report for benign disease. J Endourol 1993;7:521-6. [CrossRef]

5. Gettman MT, Blute ML, Chow GK, Neururer R, Bartsch G, Peschel R. Robotic-assisted laparoscopic partial nephrectomy: technique and initial clinical experience with DaVinci robotic system. Urology 2004;64:914-8. [CrossRef]

6. Liu JJ, Leppert JT, Maxwell BG, Panousis P, Chung BI. Trends and perioperative outcomes for laparoscopic and robotic nephrectomy using the National Surgical Quality Improvement Program (NSQIP) database. Urol Oncol 2014;32:473-9. [CrossRef]

7. Rossi SH, Klatte T, Usher-Smith J, Stewart GD. Epidemiology and screening for renal cancer. World J Urol 2018;36:1341-53. [CrossRef]

8. McGuinness LA, Prasad Rai B. Robotics in urology. Ann R Coll Surg Engl 2018;100:38-44. [CrossRef]

9. Banapour P, Abdelsayed GA, Bider-Canfield Z, Elliott PA, Kilday PS, Chien GW. Nephrometry score matched robotic vs. laparoscopic vs. open partial nephrectomy. J Robot Surg 2018;12:679-85.
10. Bravi CA, Larcher A, Capitanio U, Mari A, Antonelli A, Artibani W, et al. Perioperative outcomes of open, laparoscopic, and robotic partial nephrectomy: a prospective multicenter observational study (The RECORd 2 Project). Eur Urol Focus 2021;7:390-6.

11. Choi SY, Jung H, You D, Jeong IG, Song C, Hong B, et al. Robotassisted partial nephrectomy is associated with early recovery of renal function: comparison of open, laparoscopic, and robot-assisted partial nephrectomy using DTPA renal scintigraphy. J Surg Oncol 2019;119:1016-23. [CrossRef]

12. Aboumarzouk OM, Stein RJ, Eyraud R, Haber GP, Chlosta PL, Somani BK, et al. Robotic versus laparoscopic partial nephrectomy: a systematic review and meta-analysis. Eur Urol 2012;62:1023-33.

13. Alimi Q, Peyronnet B, Sebe P, Cote JF, Kammerer-Jacquet SF, Khene $Z E$, et al. Comparison of short-term functional, oncological, and perioperative outcomes between laparoscopic and robotic partial nephrectomy beyond the learning curve. J Laparoendosc Adv Surg Tech A 2018;28:1047-52. [CrossRef]

14. Wu Z, Li M, Song S, Ye H, Yang Q, Liu B, et al. Propensity-score matched analysis comparing robot-assisted with laparoscopic partial nephrectomy. BJU Int 2015;115:437-45. [CrossRef]

15. Kutikov A, Uzzo RG. The R.E.N.A.L. nephrometry score: a comprehensive standardized system for quantitating renal tumor size, location and depth. J Urol 2009;182:844-53. [CrossRef]

16. Ficarra V, Novara G, Secco S, Macchi V, Porzionato A, De Caro R, et al. Preoperative aspects and dimensions used for an anatomical (PADUA) classification of renal tumours in patients who are candidates for nephron-sparing surgery. Eur Urol 2009;56:786-93.

17. Ficarra V, Porpiglia F, Crestani A, Minervini A, Antonelli A, Longo N, et al. The Simplified PADUA REnal (SPARE) nephrometry system: a novel classification of parenchymal renal tumours suitable for partial nephrectomy. BJU Int 2019 Apr 9 [Epub ahead of print], doi: 10.1111/bju.14772. [CrossRef]

18. Levey AS, Bosch JP, Lewis JB, Greene T, Rogers N, Roth D. A more accurate method to estimate glomerular filtration rate from serum creatinine: a new prediction equation. Modification of Diet in Renal Disease Study Group. Ann Intern Med 1999;130:461-70.

19. Paner GP, Stadler WM, Hansel DE, Montironi R, Lin DW, Amin MB. Updates in the eighth edition of the tumor-node-metastasis staging classification for urologic cancers. Eur Urol 2018;73:560-9.

20. Dindo D, Demartines N, Clavien PA. Classification of surgical complications: a new proposal with evaluation in a cohort of 6336 patients and results of a survey. Ann Surg 2004;240:205-13.

21. Khalifeh A, Autorino R, Hillyer SP, Laydner H, Eyraud R, Panumatrassamee $\mathrm{K}$, et al. Comparative outcomes and assessment of trifecta in 500 robotic and laparoscopic partial nephrectomy cases: a single surgeon experience. J Urol 2013;189:1236-42. [CrossRef]

22. Xia L, Talwar R, Taylor BL, Shin MH, Berger IB, Sperling CD, et al. National trends and disparities of minimally invasive surgery for localized renal cancer, 2010 to 2015. Urol Oncol 2019;37:182.e17182.e27. [CrossRef]

23. Volpe A, Blute ML, Ficarra V, Gill IS, Kutikov A, Porpiglia F, et al. 
Renal ischemia and function after partial nephrectomy: a collaborative review of the literature. Eur Urol 2015;68:61-74. [CrossRef]

24. Cao J, Zhu S, Ye M, Liu K, Liu Z, Han W, et al. Comparison of renal artery vs renal artery-vein clamping during partial nephrectomy: a system review and meta-analysis. J Endourol 2020;34:523-30.

25. Leal Ghezzi T, Campos Corleta O. 30 years of robotic surgery. World J Surg 2016;40:2550-7. [CrossRef]

26. Mir SA, Cadeddu JA, Sleeper JP, Lotan Y. Cost comparison of robotic, laparoscopic, and open partial nephrectomy. J Endourol 2011;25:447-53. [CrossRef]
27. Laydner H, Isac W, Autorino R, Kassab A, Yakoubi R, Hillyer S, et al. Single institutional cost analysis of 325 robotic, laparoscopic, and open partial nephrectomies. Urology 2013;81:533-8. [CrossRef]

28. Hanzly M, Frederick A, Creighton T, Atwood K, Mehedint D, Kauffman EC, et al. Learning curves for robot-assisted and laparoscopic partial nephrectomy. J Endourol 2015;29:297-303. [CrossRef]

29. Lavery HJ, Small AC, Samadi DB, Palese MA. Transition from laparoscopic to robotic partial nephrectomy: the learning curve for an experienced laparoscopic surgeon. JSLS 2011;15:291-7. [CrossRef] 